\title{
Effect of Al-5Ti-B-RE Grain Refiner on the Microstructures and Properties of AICuCoCrFeNi High Entropy Alloys
}

\author{
Anmin $\mathrm{Li}^{1, \mathrm{a}}$, Qifeng Zheng ${ }^{1, \mathrm{~b}}$, Ruohuai Chen ${ }^{1, \mathrm{c}}$, Long Meng ${ }^{1, \mathrm{~d}}$, Ding Ma ${ }^{1, \mathrm{e}}$, \\ Yuwei Huang ${ }^{1, f}$ \\ ${ }^{1}$ College of Materials Science and Technology, Guangxi University, Nanning 530004, China \\ aemail:lamanny@126.com, bemail:909045472@qq.com, cemail:1025823140@qq.com \\ demail:627208253@qq.com, eemail:873645740@qq.com, ${ }^{\mathrm{f}}$ email:303091098@qq.com
}

Keywords: High entropy alloys; Grain refinement; Microstructure; Compressive properties

\begin{abstract}
A series of AlCrFeCoNiCu High-entropy Alloys added Al-5Ti-B-RE grain refiner were prepared by vacuum arc furnace. The microstructures of the series of as-cast AlCrFeCoNiCu alloys are typical dendrites and are constituted by two kinds of solid solution ( $\alpha$ phase and $\beta$ phase). $\alpha$ phase is body-centered cubic (bcc) structure composed of $\mathrm{Al}, \mathrm{Cr}, \mathrm{Co}, \mathrm{Fe}, \mathrm{Ni}$ and a few $\mathrm{Cu}$, and $\beta$ phase is face-centered cubic (fcc) which enriches $\mathrm{Cu}$. With the increase of Al-5Ti-B-RE, the region of aphase becomes larger. When the content of Al-5Ti-B-RE is $0.4 \%(\mathrm{wt})$, the volume ratio values of $\alpha$ phase increases, moreover, $\alpha$ phase and $\beta$ phase evenly distribute, and either the compressive strength (2.28GPa) or the compressive ratio (20.95\%) is maximized. Fan pattern appears in the fracture morphologies of these alloys, and it is cleavage fracture. These alloys belong to brittle materials.
\end{abstract}

\section{Introduction}

High-entropy Alloys (HEAs) [1] (namely, high-entropy alloy with multi-principal elements [2 4], or the Multi-component Alloys with High Entropy of Mixing [5, 6]) possess simple crystal structures, ease of nanoprecipitation and amorphous structure, and predominant properties in high hardness and compressive strength, superior resistance to temper softening, wear, oxidization and corrosion[7 10]. HEAs have been studied by many scholars in recent years, and a lot of research results have been reported. However, there are a few studies related to refine the microstructure of HEAs. As we know, the microstructures of HEAs appear typical coarse dendrites [4], and HEAs belong to brittle materials. It is essential to improve the toughness of HEAs. This paper studies the effect of Al-5Ti-B-RE grain refiner on the microstructures and properties of the AlCrFeCoNiCu HEA. This has important reference value to study the microstructure and properties of HEAs.

\section{Materials and Experimental Details}

\section{Materials}

Raw materials are pure $\mathrm{Al}, \mathrm{Cr}, \mathrm{Fe}, \mathrm{Co}, \mathrm{Ni}, \mathrm{Cu}$ and $\mathrm{Al}-5 \mathrm{Ti}-\mathrm{B}-\mathrm{RE}$ grain refiner. Their purities are as follows: 99.99\%, 99.98\%, 99.99\%, 99.97\%, 99.999\%, 99.999\% and 99.9\%. Al-5Ti-B-RE grain refiner was produced by XuZhou HuaZhong Aluminum Co. Ltd. and the component of it is shown as Table 1.

Table1 The component of Al-5Ti-B-RE (wt\%)

\begin{tabular}{|c|c|c|c|c|c|c|c|}
\hline Element & $\overline{\mathrm{Ti}}$ & B & $\mathrm{RE}$ & $\overline{\mathrm{Fe}}$ & $\mathrm{Si}$ & & $\mathrm{Al}$ \\
\hline $\begin{array}{l}\text { Percentag } \\
\text { e }\end{array}$ & 5.01 & 0.99 & 0.9 & 0.18 & 0.13 & 0.01 & Margin \\
\hline \multicolumn{8}{|c|}{ Table 2 The number of spamples } \\
\hline \multicolumn{2}{|c|}{ Sample number } & 0 & 1 & 2 & 3 & 4 & 5 \\
\hline \multicolumn{2}{|c|}{ Al-5Ti-B-RE (wt\%) } & 0 & 0.1 & 0.2 & 0.3 & 0.4 & 0.5 \\
\hline
\end{tabular}


AlCrFeCoNiCu HEAs added different content of Al-5Ti-B-RE were prepared by Electric Arc Furnace with a water-colded copper crucible. The operations were conducted in a vacuum of $0.01 \mathrm{~atm}$ after the crucible had been purged 3 times with argon. Melting was performed at least 5 times to ensure that the alloys were highly homogeneous. The solidified samples were about $\Phi 20 \mathrm{~mm} \times 10 \mathrm{~mm}$. Their numbers are shown in Table 3, and the content of Al-5Ti-B-RE is the percentage of the total weight of the sample. An X-ray diffractometer (XRD, D/Max2500V, Japan) was used for the phase identification with the $2 \theta$ scan ranging from $30^{\circ}$ to $80^{\circ}$ at a speed of $8^{\circ} \mathrm{min}^{-1}$. The microstructures were studied by a Hitachi S-3400N scanning electron microscope (SEM) and energy dispersive spectrum analysis (EDS) (EDAX PV8200) and typical radiation condition was $20 \mathrm{kV}$ and $200 \mathrm{~mA}$ with a copper target, and SU-8020/X-MAX 80 field emission SEM. Room temperature compressive properties were tested on an Instron 8801 testing machine with a loading speed of $1.0 \mathrm{~mm} / \mathrm{min}$. The test specimens were cylindrical, $\Phi 5 \mathrm{~mm} \times 10 \mathrm{~mm}$. Three compression tests were performed to obtain the average value.

\section{Results and discussion}

\section{SEM analysis}

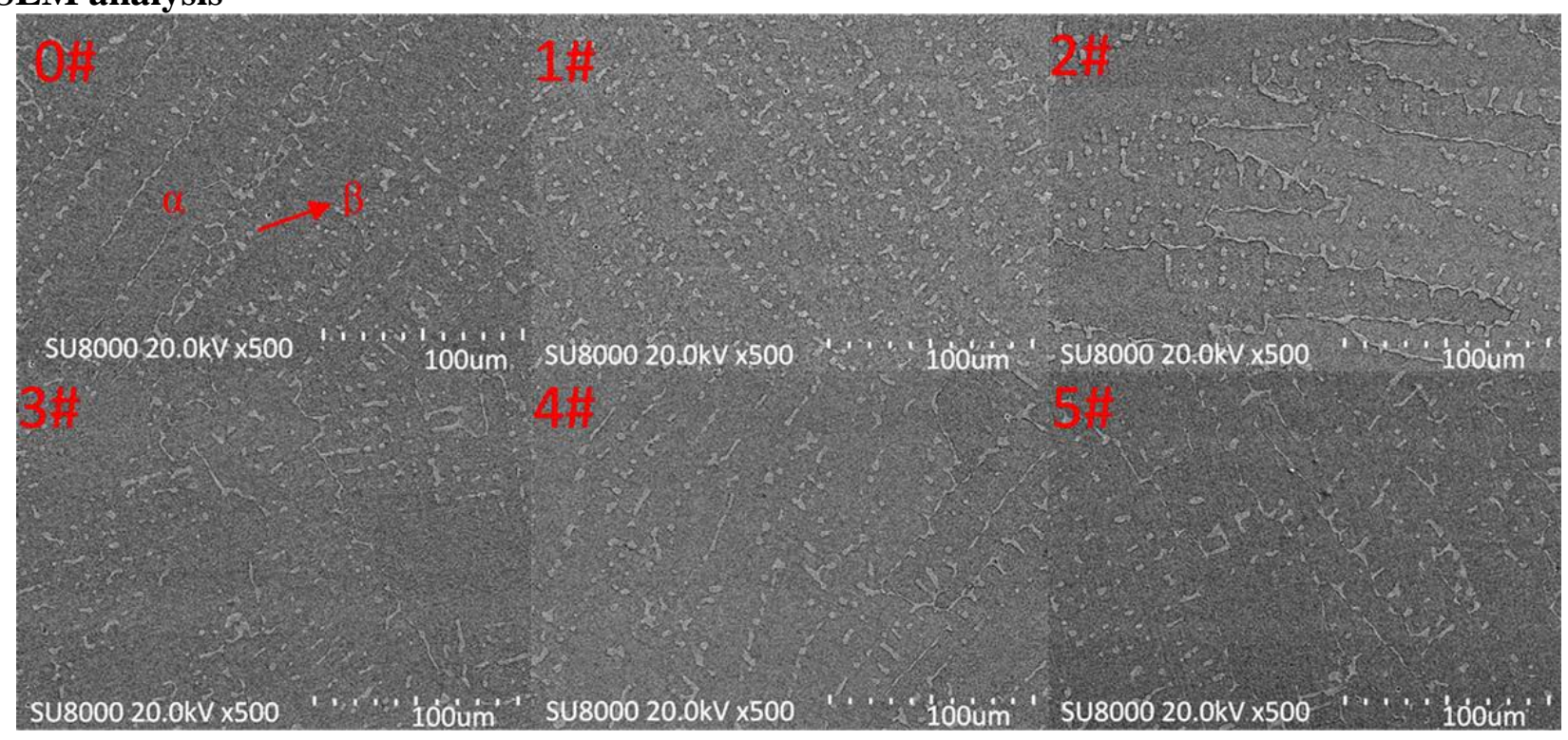

Fig.1.SEM electron images of the series of $\mathrm{AlCrFeCoNiCu}$ alloys

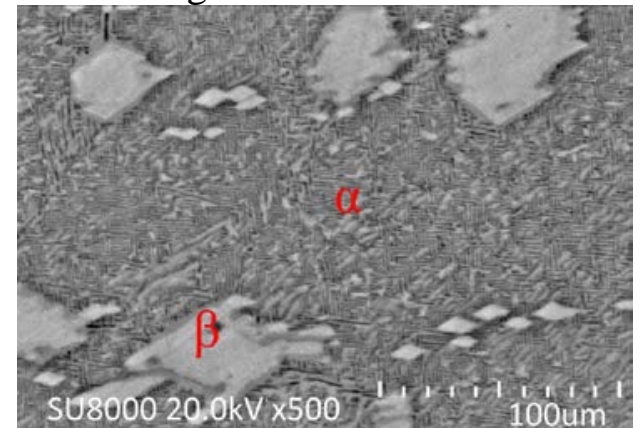

Fig. 2 High multiple microstructure of AlCrFeCoNiCu alloy

( $\alpha$ :dendrite phase; $\beta$ :inter-dendrite phase)

Tab.3 Distributions of elements in dendrite and interdendrite of the AlCrFeCoNiCu alloy (atom,\%)

\begin{tabular}{cllllll}
\hline location & $\mathrm{Al}$ & $\mathrm{Cr}$ & $\mathrm{Fe}$ & $\mathrm{Co}$ & $\mathrm{Ni}$ & $\mathrm{Cu}$ \\
\hline dendrite $(\alpha)$ & 22.43 & 16.89 & 15.96 & 17.79 & 17.31 & 9.61 \\
Interdendrite $(\beta)$ & 14.96 & 4.59 & 6.11 & 7.09 & 14.73 & 52.52 \\
\hline
\end{tabular}


The SEM backscattered electron images of the series of as-cast AlCrFeCoNiCu alloys are shown in Fig.1 and Fig.2. They are typical dendrites. Acoording to Distributions of elements in dendrite and interdendrite are shown in Table 1. Cu element segregates in the interdendrite. With the increase of Al-5Ti-B-RE, the region of dendrite becomes larger.

\section{XRD analysis}

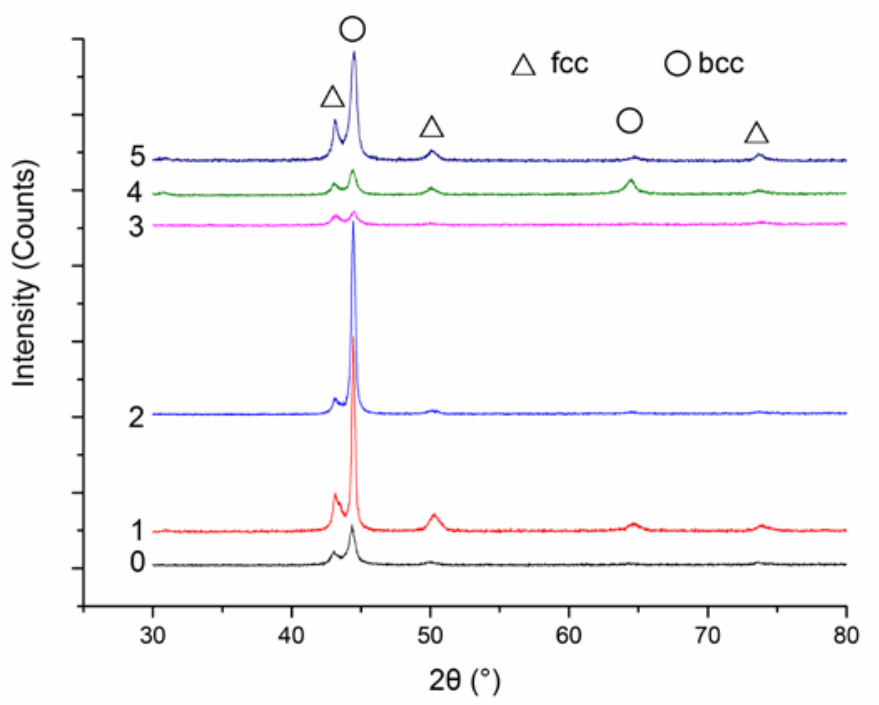

Fig. 2 XRD patterns of the series of AlCrFeCoNiCu alloys

Acoording to the results of XRD analysis, the as-cast microstructure is constituted by two kinds of solid solution. One is body-centered cubic (bcc) structure solid solution, the other is face-centered cubic (fcc) solid solution. Combined the results of EDS, inter-dendrite phase (aphase) is fcc, which enriches $\mathrm{Cu}$ whose crystal structure is fcc with solution element $\mathrm{Al}, \mathrm{Cr}, \mathrm{Co}, \mathrm{Fe}$ and $\mathrm{Ni}$. Dendrite phase ( $\beta$ phase) is bcc composed of $\mathrm{Al}, \mathrm{Cr}, \mathrm{Co}, \mathrm{Fe}, \mathrm{Ni}$ and a few $\mathrm{Cu}$. According to Jade software, the volume fractions of $\alpha$ and $\beta$ phases were calculated, and the results are shown in Table 4.

Table 4 Volume ratio of phases and properties of the series of AlCrFeCoNiCu alloys

\begin{tabular}{ccccc}
\hline \multirow{2}{*}{ Sample } & \multicolumn{2}{c}{$\begin{array}{c}\text { Volume ratio of } \\
\text { phases }\end{array}$ \% $)$} & \multicolumn{2}{c}{$\begin{array}{c}\text { compressive } \\
\text { properties }\end{array}$} \\
\cline { 2 - 5 } & $\alpha$ & $\beta$ & $\sigma_{\max }(\mathrm{GPa})$ & $\varepsilon(\%)$ \\
\hline 0 & 88.73 & 11.22 & 2.01 & 17.19 \\
1 & 91.42 & 8.58 & 1.82 & 13.34 \\
2 & 90.09 & 9.91 & 1.99 & 13.47 \\
3 & 93.01 & 6.99 & 1.94 & 16.06 \\
4 & 93.16 & 6.84 & 2.28 & 20.95 \\
5 & 94.21 & 5.79 & 1.93 & 13.95 \\
\hline
\end{tabular}

\section{Properties of the series of AlCrFeCoNiCu alloys}

Room temperature compressive stress-strain curves and compressive properties of the series of AlCrFeCoNiCu alloys are shown in Fig.3 and Table 2. Al-5Ti-B-RE affects compressive properties of alloys, and the compressive strength values of most of the alloys decrease than that of alloy unadded Al-5Ti-B-RE except the No.4 sample. Furthermore, compared to the relation of volume ratio of phases and compressive properties, when the volume ratio values of $\alpha$ phase increases, moreover, $\alpha$ phase and $\beta$ phase evenly distribute (such as No.4 in table 2 and Fig.1.), either the compressive strength or the compressive ratio is maximized. More $\alpha$ phase is useful to improve the strength of alloy because the structure of $\alpha$ phase is bcc whose solid solution strengthening is more than that of fcc[11-13]. Because $\beta$ phase enriched $\mathrm{Cu}$ distributes in the grain boundary, and it plays a role of solder flux to reduce the brittleness of the alloys[14]. This result confirms the effect of $\mathrm{Cu}$ in HEAs in document [15]. 


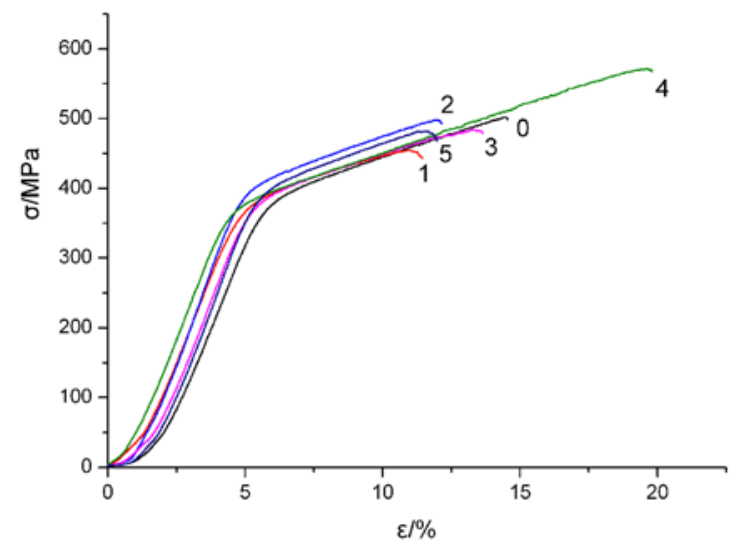

Fig.3. Compressive stress-strain curves of the series of AlCrFeCoNiCu alloys
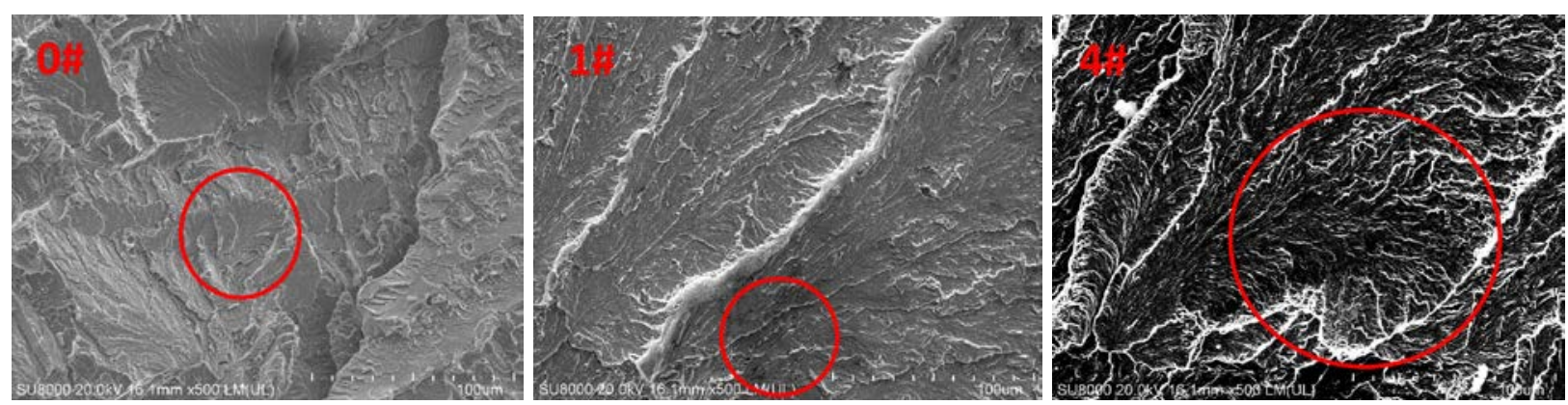

Fig.4. Scanning electron micrograph of compressive fracture surface of the alloys

Fracture morphologies of some samples are shown in Fig.4. The fan pattern appears (as the region of red circles in Fig.4) that is the feature of cleavage fracture, and it indicates that these alloys belong to brittle materials.

\section{Conclusions}

A series of AlCrFeCoNiCu added Al-5Ti-B-RE grain refiner High-entropy Alloys were prepared by vacuum arc furnace. The microstructures of the series of as-cast $\mathrm{AlCrFeCoNiCu}$ alloys are typical dendrites and are constituted by two kinds of solid solution ( a phase and $\beta$ phase). a phase is body-centered cubic (bcc) structure composed of $\mathrm{Al}, \mathrm{Cr}, \mathrm{Co}, \mathrm{Fe}, \mathrm{Ni}$ and a few $\mathrm{Cu}$, and $\beta$ phase is face-centered cubic (fcc) which enriches $\mathrm{Cu}$. With the increase of Al-5Ti-B-RE, the region of a phase becomes larger. When the content of Al-5Ti-B-RE is $0.4 \%(\mathrm{wt})$, the volume ratio values of $\alpha$ phase increases, moreover, $\alpha$ phase and $\beta$ phase evenly distribute, and either the compressive strength (2.28GPa) or the compressive ratio (20.95\%) is maximized. Fan pattern appears in the fracture morphologies of these alloys, and it is cleavage fracture. These alloys belong to brittle materials.

\section{Acknowledgements}

This work was financially supported by the Higher Education Teaching Reform Project of Guangxi Zhuang Autonomous Region of China (2013JGZ104), Project Sponsored by open foundation of Guangxi Key Laboratory for Advanced Materials and Manufacturing Technology (13-A-02-03) and the Scientific Research Foundation of Education Department of Guangxi Zhuang Autonomous Region (2013YB012).

\section{References}

[1] J.W.Yeh, S.K.Chen, S.J. Lin, J.Y.Gan, T.S.Chin, T.T.Shun, C.H.Tsau, S.Y. Chang. Nanostructured high-entropy alloys with multi-principal elements-novel alloy design concepts and outcomes [J]. Advanced Engineering Materials, 2004 (5) 299-303. 
[2] J.W.Yeh, S.K.Chen, J.Y.Gan, S.J. Lin ,T.S.Chin, T.T.Shun, C.H.Tsau, S.Y. Chang. Formation of simple crystal structures in Cu-Co-Ni-Cr-Al-Fe-Ti-V alloys with multiprincipal metallic elements [J]. Metallurgical Materials Transactions A, 2004 (35A) 2533-2536.

[3] J.W.Yeh, R.K.Chen and S.J. Lin: Overview of the development of the high-entropy alloys [J]. Magazine of Industrial Materials, 2005224 71-79

[4] A.m.Li and X.Y. Zhang: Effect of $\mathrm{Al}$ on the microstructure and hardness of $\mathrm{Al}_{x} \mathrm{CrCuFeNi}$ high-entropy alloy system [J]. Hot Working Technology, 20084 26-28.

[5] J.Y. Yang, Y.J.Zhou, Y.Zhang , G.L.Chen. Solid Solution Formation Criteria in the Multicomponent Alloys with High Entropy of Mixing[J]. Material Technology and Equipment of China, 20075 61-63.

[6] Y.J. Zhou, Y. Zhang, Y.L. Wang , G.L.Chen. Microstructure and compressive properties of multicomponent $\mathrm{Al}_{x}(\mathrm{TiVCrMnFeCoNiCu})_{100-x}$ high-entropy alloys[J]. Materials Science and Engineering A, 2007 454-455 260-265.

[7] P. K. Huang, J.W. Yeh , T. T. Shun, S.K.Chen. Multi-principal-element alloys with improved oxidation and wear resistance for thermal spray coating[J]. Advanced Engineering Materials, 2004 1-2 74-78.

[8]C.Y. Hsu, J.W.Yeh, S.K.Chen and T.T.Shun. Wear resistance and high-temperature compression strength of FCC CuCoNiCrAl0.5Fe alloy with boron addition [J]. Metallurgical Materials Transactions A, 2004 35A 1465-1469.

[9] Y.Y. Chen, U.T. Hong, H.C. Shih, J.W. Yeh, T. Duval. Electrochemical kinetics of the high entropy alloys in aqueous environments-acomparison with type 304 stainless steel [J]. Corrosion Science, 200511 2679-2699.

[10] J.M.Wu, S.J. Lin, J.W.Yeh, S.K.Chen, Y.S.Huang ,H.C.Chen. Adhesive wear behavior of AlxCoCrCuFeNi high-entropy alloys as a function of aluminum content [J]. Wear, 2006 261(5-6) 513-519.

[11] T. Courtney. Mechanical Behavior of Materials[C]. McGraw-Hill: New York, 1990. 173-184.

[12] G.E. Dieter, Mechanical Metallurgy[C]. McGraw-Hill:New York,1988.117-121.

[13] G.E. Dieter, Mechanical Metallurgy[C]. McGraw-Hill:New York,1988.208-212.

[14] Anmin Li, Ding Ma,Qifeng Zheng.Effect of Cr on Microstructure and Properties of a Series of

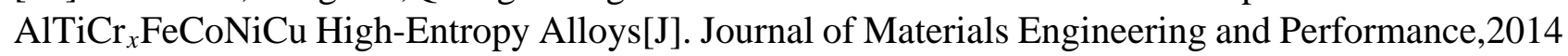
23 1197-1203

[15] Liu Yuan , Chen Min , Li Yanxiang ,Chen Xiang. Microstructure and Solidif ication Mode of AlTiFeNiCuCrx High-entropy Alloy with Multi-Principal Elements[J]. Specical Casting \& Non-ferrous Alloys, 2008 Annual Meeting Issue,87-89 